\title{
Effect of the terroir and the harvest time on the Kékfrankos grape berries sensorial properties in Eger (Hungary)
}

\author{
Barócsi, Z. \\ Szent István University, Institute of Horticulture; H-2100 Gödöllö, Páter Károly 1., \\ Barocsi.Zoltan@mkk.szie.hu
}

\begin{abstract}
Summary: In this research the effects of the production site "terroir" and the harvest time on the most important organoleptic properties of the berries of Kékfrankos (Blaufrankish) grape variety were observed. The follow-up of the maturation process in a given parcel can effectively supplemented by the results of sensorial evaluations of the grape berries. In most cases, the tasters found significant differences in sensorial characteristics of the berries due to the harvest time, although the trends of each parcels were different. Significant differences were frequently found in the result of the observed terroirs.
\end{abstract}

Keywords: grape berry, sensorial analysis, berry skin, pulp, seed, terroir effect, harvest timing

\section{Introduction}

High quality red wines can be only made from basic materials harvested at the time of the phenolic ripeness stage. In the correct choice of the harvest date, we can complete the grapes sensory analysis results with the traditional chemical analyses. In our experimentation, we studied the effects of the territory and the harvest timing on the physical properties and sensorial characteristics of Vitis vinifera $L$. cv. Kékfrankos. The grape berry sensory evaluation method was developed by the French research institute ICV. The researchers stated a close correlation between the sensorial properties of the wines and the grapes from which the wines were made (Rousseau and Delteil, 2000/a). According to Rousseau (2001) the sensorial evaluation is essentially based on the consecutive ratings of the berry pulp, berry skin and the pulps. During the tastings, the visual characteristics, the sensory and physical properties of the pulp, skin and seed are evaluated. In the method of Rousseau-Delteil (2000/b) the sensorial analyses determined the sugar and acid intensity, the fruity and vegetal flavours of the pulp, the tannin intensity, acidity, astringency, vegetal, fruity character and the texture of the berry skin. Martinez (2002) developed an easier method, that allows an easy evaluation of only nine important parameters of the berries. However, the method of Le Moigne et al. (2008) concern about 30 different parameters of the yield. In the case of the Cabernet franc they concluded a very close relationship between the sensorial character of the wine and the berries Morisson and Noble (1990) examined the leaf and cluster shading of the composition of Cabernet sauvignon grape and wines. In the sensory evaluation they could detect differences in crushed fresh grapes between the aroma of the control and each of the shade treatments. Similarly, wines made from fruit of the control treatment were significantly different in aroma and flavour from wines made from the three shading treatments. Deloire, A. (2013) proposes a monitoring system with various indicators, coupled with appropriate analytical data measurements such as berry fresh mass or volume, brix, sugar loading, evolution of titrable acidity, malic acid tartaric acid, $\mathrm{pH}$, colour evolution, anthocyanins, tannins, berry tasting, etc.) enable decision makers to determine the optimum harvesting date, a major consideration in determining potential optimal harvesting dates and optimal ripening levels according to the desired style of wine.

\section{Materials and methods}

\section{Experimental sites}

In our experiment, the following four different terroirs were compared in Eger wine district: Kőlyuktető(1), Szomolya(2) Nagyeged-hill low(3) and Nagyeged-hill top(4). All parcels are described by north-south row lines. The applied training system was the umbrella pruned with two long canes. The examined red grape variety was the Vitis vinifera cv. Kékfrankos (Blaufrankish), grefted on Berlandieri x Riparia T.5.C root-stock. 


\section{Vintages}

Both vintages $(2010,2011)$ showed extreme values compared to the average of many years. In 2010, the monthly average temperature values - except for July - remained below the long term average, while in 2011 the opposite trend was observed. Although the number of sunshine hours was favourable both years, in 2011 an outstanding value (2356 hours) was observed. The biggest difference between the two years was found in the precipitation. In 2010 a significantly greater amount of precipitation has emerged than in previous years, however in the extremely dry 2011 only $390 \mathrm{~mm}$ of rain fell during the whole season.

\section{Samplings}

We collected a simple of 300 berries from the different spots of plantations, from the two sides of the canopy walls, from the different bunch levels of the shoots and from the different cluster zones. These representative samplings were directly analysed after delivery. During the experiment, four times from each parcels (five times in 2011) samples were collected according to the following dates presented in the table 1.

Table 1: Dates of the samplings (harvests) in both examined years

\begin{tabular}{|l|l|l|}
\hline & 2010 & 2011 \\
\hline 1. First harvest & $26^{\text {th }}$ of september & $16^{\text {th }}$ of september \\
\hline 2. Second harvest & $5^{\text {th }}$ of october & $22^{\text {nd }}$ of september \\
\hline 3. Third harvest & $15^{\text {th }}$ of october & $3^{\text {rd }}$ of october \\
\hline 4. 4th harvest & $25^{\text {th }}$ of october 25 & $14^{\text {th }}$ of October \\
\hline 5. 5th harvest & - & $24^{\text {th }}$ of October \\
\hline
\end{tabular}

\section{Determination and evaluation of examined parameters}

The grapes sensorial properties were evaluated on a fivepoint scale. It is important to emphasise, that in the case of unpleasant flavours (e.g., vegetal character, astringency), the highest score means the lowest concentration. In the berry skins we evaluated the tannin intensity, astringency, vegetal and fruity character. In the pulp the sugar intensity, acidity, acid composition, vegetal, fruity and spicy characters were evaluated, while during the seed tastings, we focused on the tannin intensity and astringency.

The sensorial analyses were organised in the KRF Research Institute for Viticulture and Oenology, Eger. From the collected samples, 20 berries were taken randomly by 6 tasters, so all samples were analysed in 120 repetitions by each evaluators. The collected samples was carried out from 20 to 20 berries were taken at random, so every batch of 120 replicates were evaluated, from 1 to 5 integers. The evaluation form is shown in the table 2 .

For the statistical data processing and for the computer graphic evaluation of the obtained average values the Microsoft Excel and SPSS software's were used. First, we verified the homogeneity of the berries used as a sample by the Kruskal-Wallis test, than we examined by the Friedman's rank analysis tests, whether statistically significant differences could be verified between the different terroirs or in the same areas between the different harvest times.

Table 2: Evaluation form for berry sensorial analyses

BERRY SKIN

\begin{tabular}{|c|c|c|c|c|c|}
\hline Hardness & $\begin{array}{l}\text { Separability } \\
\text { pulp/skin }\end{array}$ & $\begin{array}{l}\text { Tannin } \\
\text { flavour } \\
\text { intensity }\end{array}$ & Astringency & $\begin{array}{l}\text { Vegetal } \\
\text { character }\end{array}$ & $\begin{array}{c}\text { Fruity } \\
\text { character }\end{array}$ \\
\hline \multicolumn{6}{|c|}{ BERRY PULP } \\
\hline Acidity & $\begin{array}{l}\text { Acid compo- } \\
\text { sition }\end{array}$ & $\begin{array}{l}\text { Vegetal } \\
\text { flavour }\end{array}$ & Fruity aromas & Spicy aromas & Juiciness \\
\hline \multicolumn{6}{|c|}{ SEEDS } \\
\hline \multicolumn{2}{|c|}{ Hardness } & \multicolumn{2}{|c|}{ Tannin-intensity } & \multicolumn{2}{|c|}{ Astringency } \\
\hline
\end{tabular}

\section{Results and discussions}

Sensorial properties of the berry skin (Figures $1 a, b, c, d, e$ )

In 2010 significant differences were found between each parcels, however the effect of the harvesting time was not so considerable. Tasters gave statistically proved lower scores for the Kölyuktető and Szomolya parcels compared with the Nagyeged-hill terroirs.. In 2011, the trend remained similar, although minor differences differences were found between the regions.

The berry skin astringency was decreasing during the course of maturation. In 2010, at the last harvesting time, especially good values occurred, while the differences between regions were decreased slightly. In 2010, the NagyEged top showed the most favourable sensorial character, however in 2011, a too astringent, unpleasant flavour appeared, probably due to the strong overriping effect.

In 2010 a progressive decrease in the berry skin vegetal character was registered during the ripening season of each parcels. In this respect, the Nagyeged hill (low and top) parcels showed slightly better results, than the samples of Kölyuktetö and Szomolya. In the samples of the last harvest time of 2011, the vegetal character became stronger, due to the intensive overriping phenomenon.

The berry skin fruity character passed through important changes during the ripening in 2010. The differences increased between parcels. By the time of the whole maturity, the fruity character became the more pronounced in the berry samples of the Nagyeged parcels. Similar trend was found in 2011; however the berries lost their fruity taste in 2011, by the time of the last harvest. (Figures $1 a, b, c, d, e$ ) 


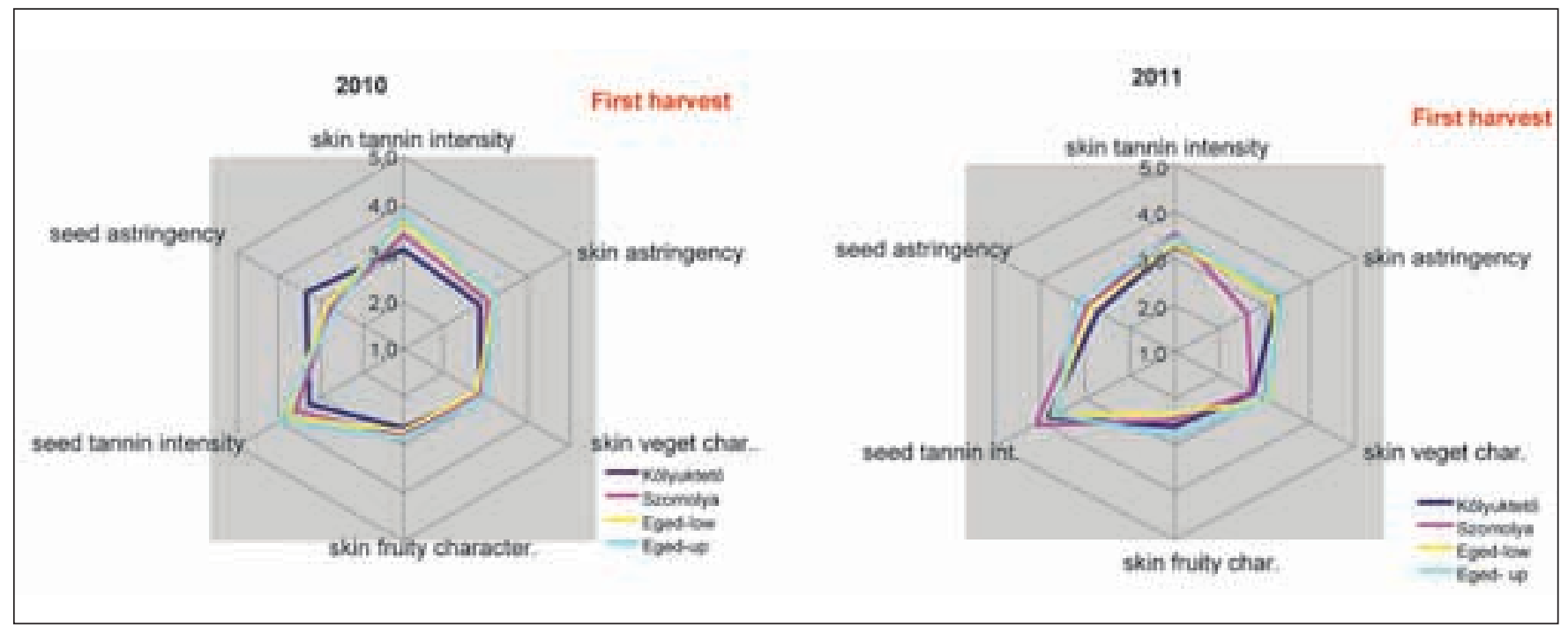

Figure 1 a: Main sensorial characters of the berry skin and the seeds (2010-2011- First harvest time)

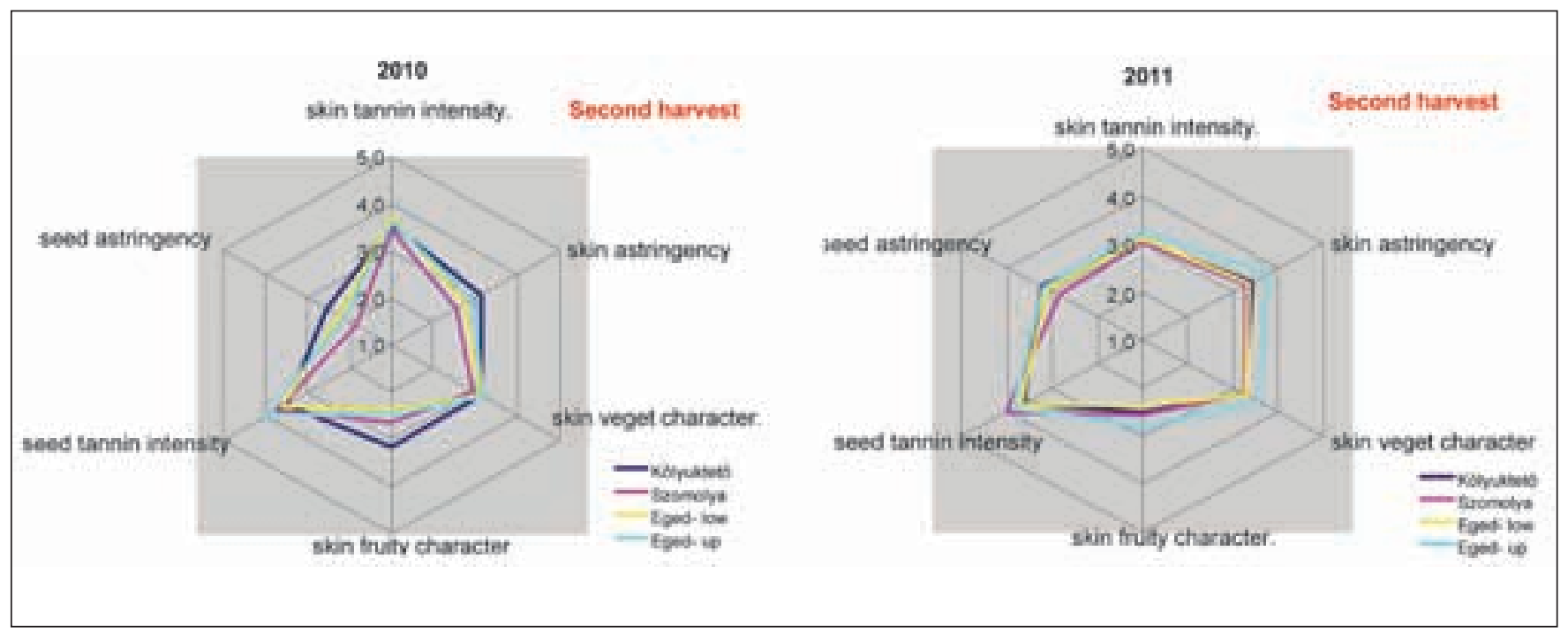

Figure $1 \boldsymbol{b}$ : Main sensorial characters of the berry skin and the seeds (2010-2011- Second harvest time)

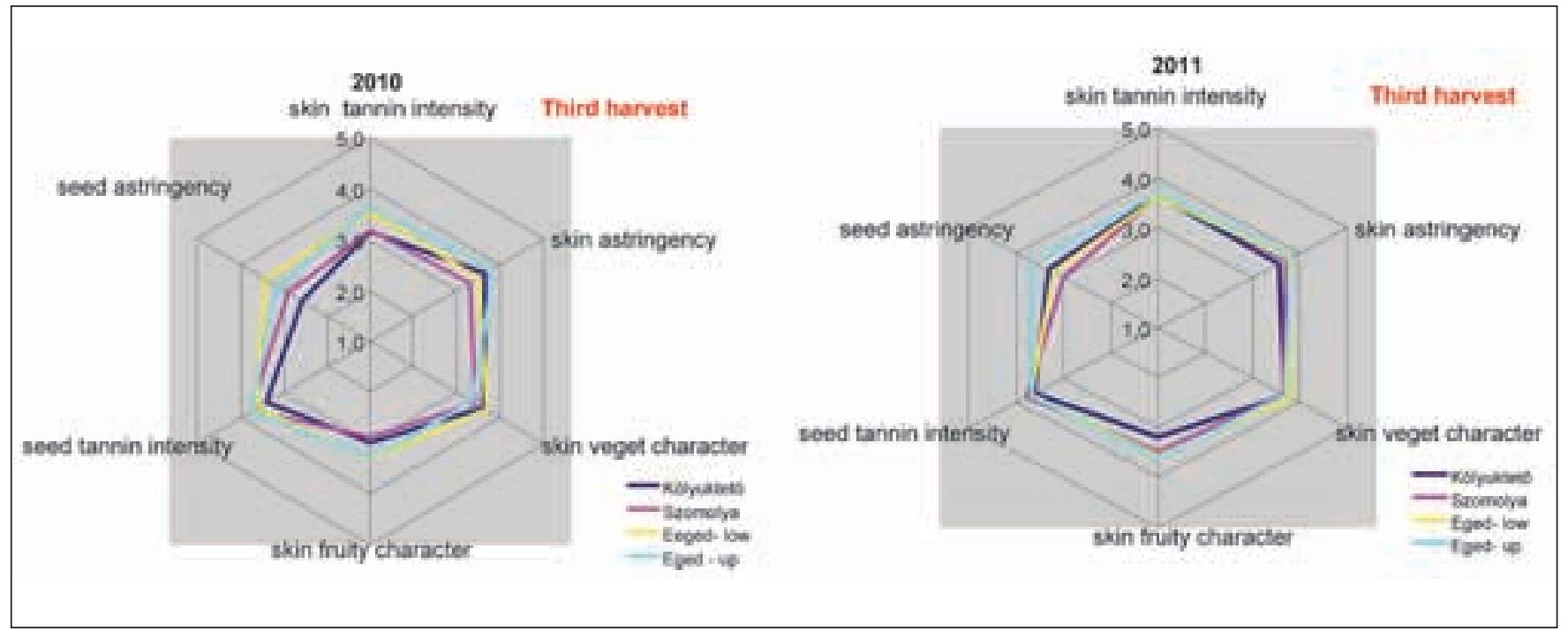

Figure 1 c: Main sensorial characters of the berry skin and the seeds (2010-2011- Third harvest time) 


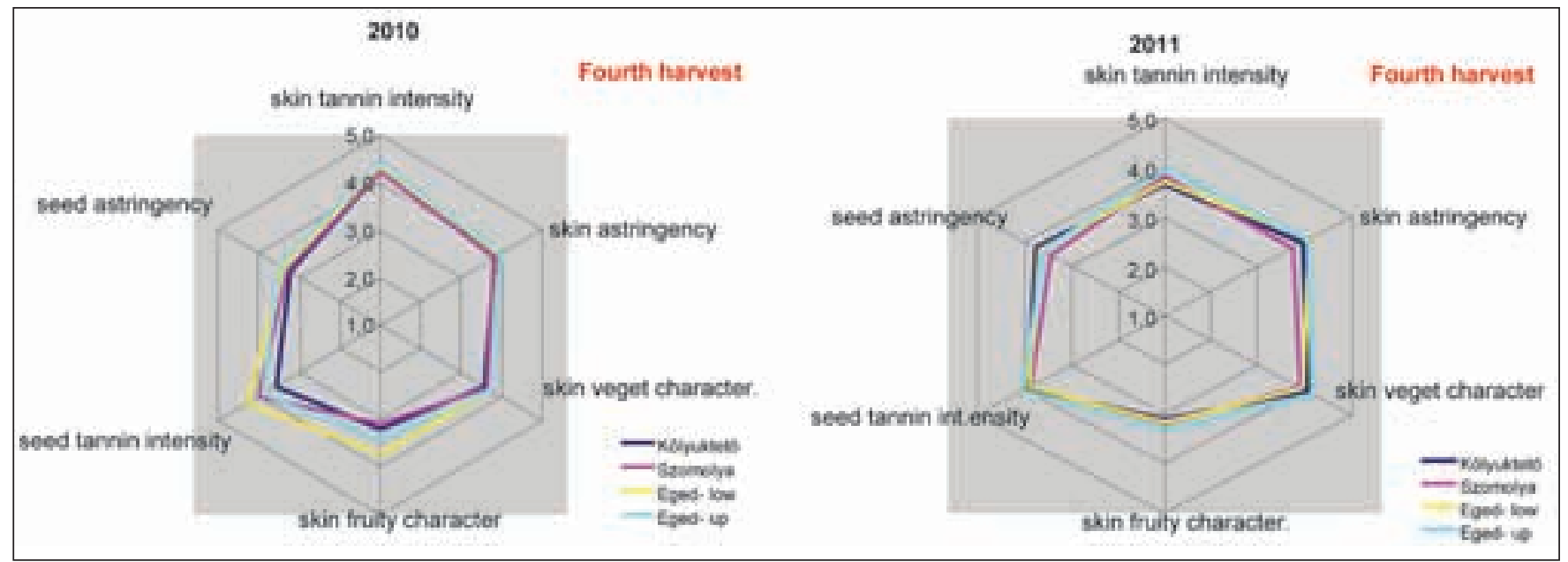

Figure 1 d: Main sensorial characters of the berry skin and the seeds (2010-2011- Fourth harvest time)

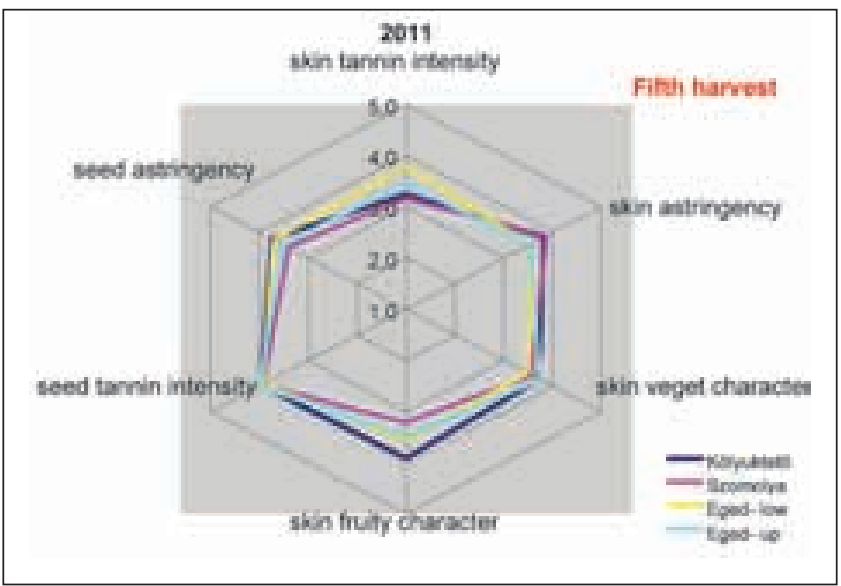

Figure 1e: Main sensorial characters of the berry skin and the seeds (2011Fifth harvest time)

\section{Sensorial properties of the berry pulp (Figures $2 a, b, c, d, e$ )}

The pulp sugar intensity greatly increased in the observed periods in all terroirs and both years. This tendency was observed in the entire ripening season in 2010 , while only by the time of the third harvest date in 2011. In the Nagyeged samples, the sugar intensity clearly increased, while the Kölyuktetö could reach the similar sugar level in 2011 only by the end of the season.

The pulp acidity in 2010, did not change significantly during ripening, and the differences between terroirs did not prove evidence. In 2011, probably due to the higher sum of temperature - the acid sensation decreased significantly during ripening. Nevertheless clear differences in the classification of the parcels could not be determined.

The acid composition showed significant changes during ripening period on each plots. The order of the terroirs was not clear. The experiment results show that it is required to avoid the strongly overriped stage for a harmonious acid composition. In 2010, the vegetal flavour of the pulp differed significantly from the berry skin. During the maturation process we observed a degradation and transformation of the compounds that are involved in the development of this flavour. In the samples of the Kölyuktetö and Szomolya parcels, this character seemed more pronounced than in the case of the two other plots. In 2011, the heavy drought proved to be unfavourable in this respect, so by the time of the last harvest date a lower score was obtained in all samples.

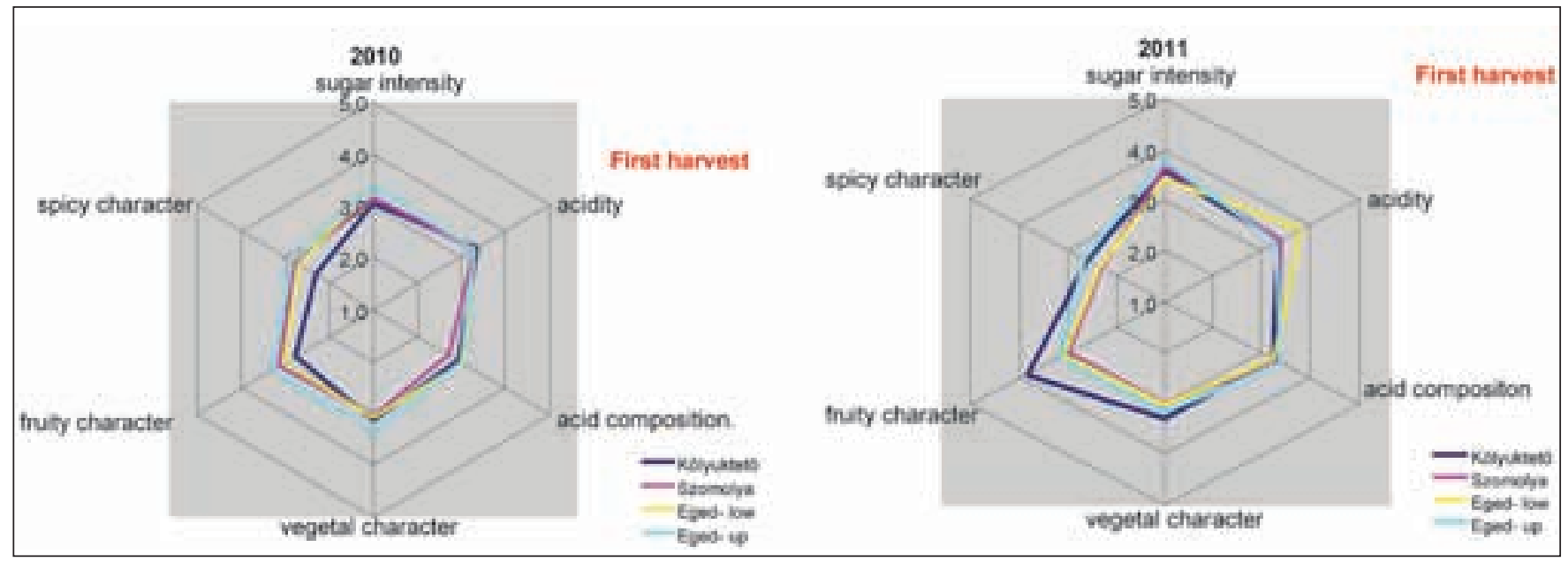

Figure 2a: Main sensorial characters of the pulp (2010-2011- First harvest time) 


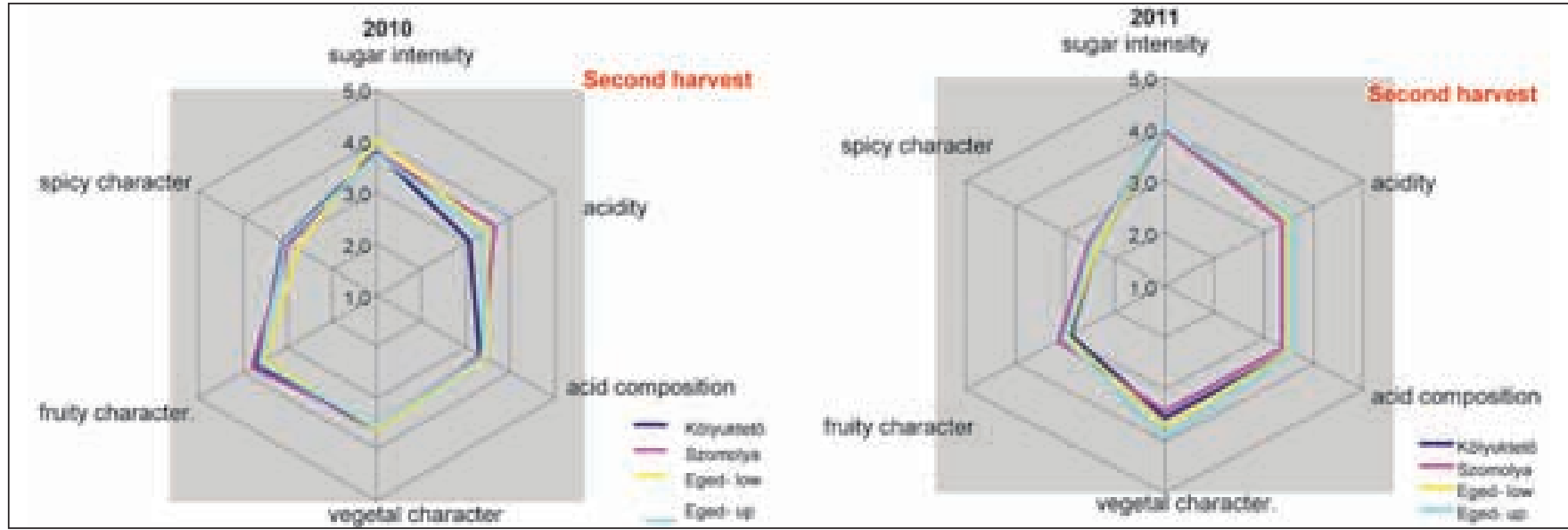

Figure 2b: Main sensorial characters of the pulp (2010-2011- Second harvest time)

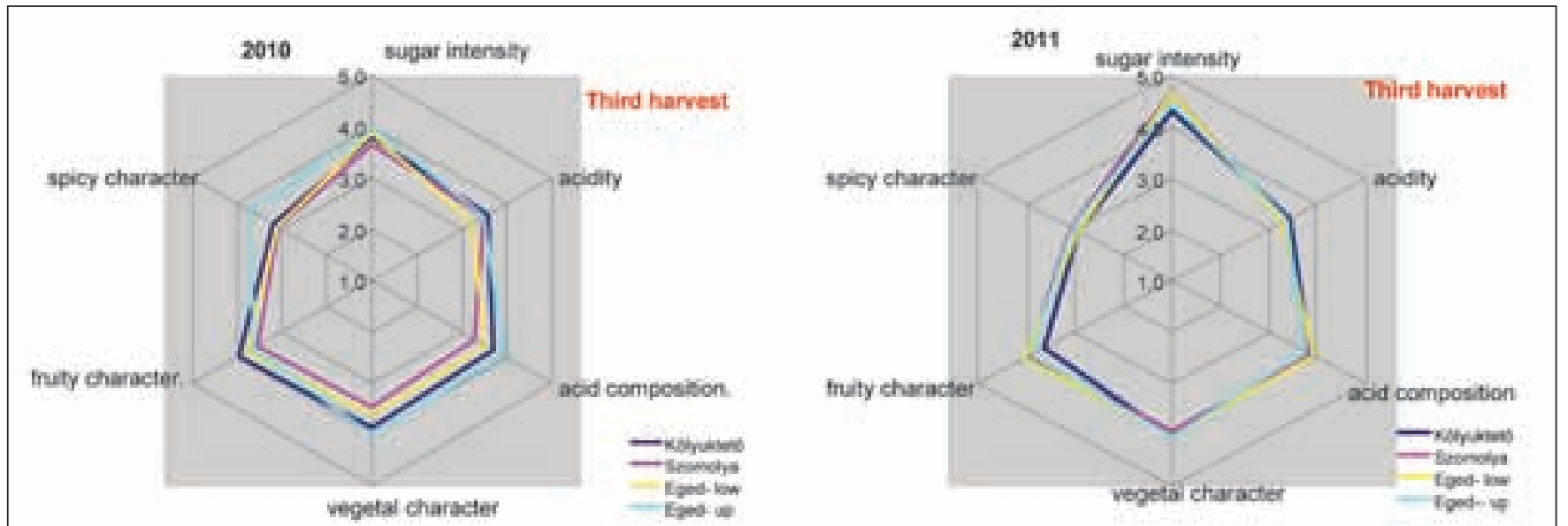

Figure 2c: Main sensorial characters of the pulp (2010-2011- Third harvest time)

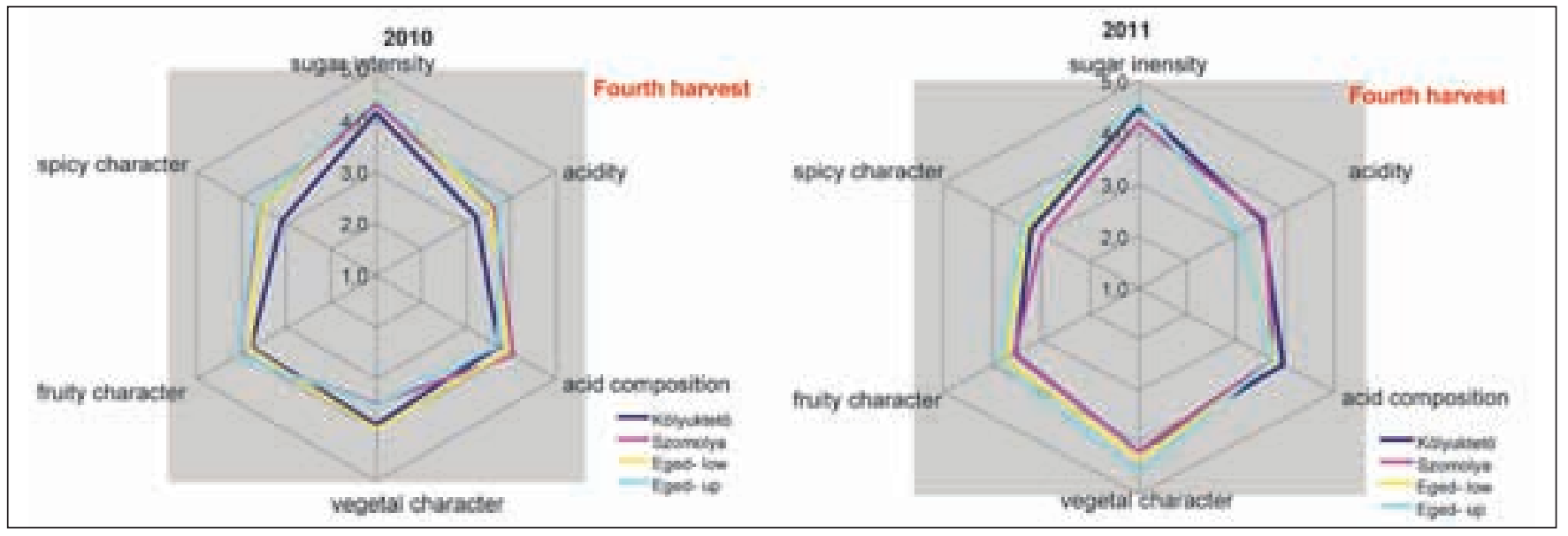

Figure 2d: Main sensorial characters of the pulp (2010-2011- Fourth harvest time)

The changes in the pulp fruity character of the samples of Nagyeged hill-low and Kőlyuktető parcels showed a saturation curve in 2010, while in the results of the Nagyegedtop and Szomolya sites larger deviations were observed. In 2011, apart from the Kölyuktető parcel, the fruity character increased in all observed sites during the entire ripening stage.
The pulp spicy taste become increasingly dominant during the ripening. The role of the harvest time was confirmed as a dominant factor of this character. Both in 2010 and 2011, the Nagyeged parcels showed outstanding results. Mainly the results of 2011 confirmed, that the spicy taste can be intensify due to the positive effect of the overriping, therefore the late harvest time samples have the higher quality potential. 


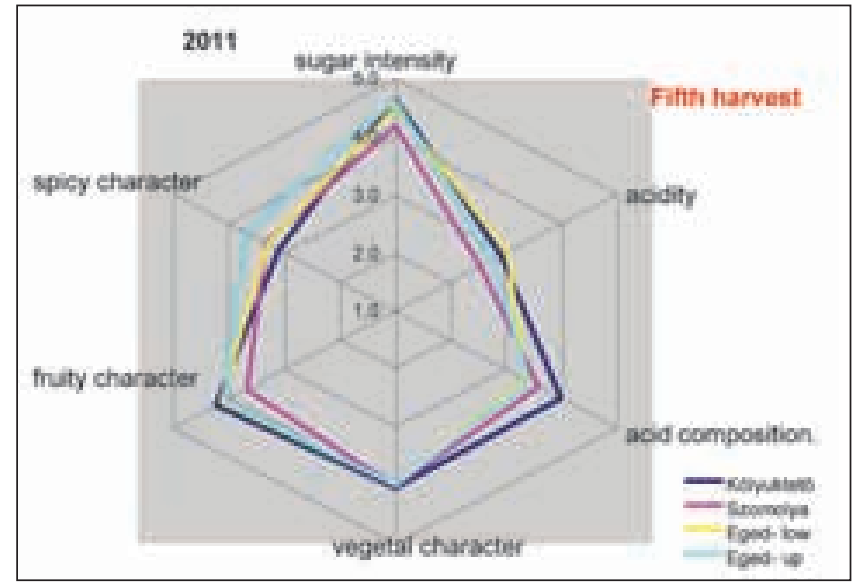

Figure 2e: Main sensorial characters of the pulp (2010-2011- Fifth harvest time)

Sensorial properties of the seeds (Figures $1 a, b, c, d, e$ )

In the development tannin intensity of the seeds, both the harvest time and the terroir played a determinate role. In 2010, the Kölyuktető samples showed the lowest scores, while the other parcels were characterized by increasing intensity of seed tannin during the whole ripening season. In 2011, the seed tannin intensity showed a large variation, so that significant differences neither between harvest dates nor between parcels were not found. During the ripening, in each observed parcels, the seed tannin intensity increased slightly, with exception of the Szomolya area. By the end of the ripening period, the statistically significant differences between each region disappeared.

In the astringency of the seed tannins very similar trends emerged in 2010: with the postponing harvest date in each region. the quality of the seed taste was improved by the fact of a lower astringency level. The significant differences between regions were somewhat decreased during the maturation. The best composition of the tannins were typical for the Nagyeged parcels (low, top), while in 2011 the Kölyuktetö also showed a positive value by the time of the end of the ripening period. Between the results of the each terroirs and harvest dates in all cases significant differences were detected.

\section{Conclusions}

In 2010, the tannin intensity of the berry skin and seed varied greatly between regions and harvest dates. In 2011, the accumulation of phenolic compounds is the maturation period was marked earlier. The best values in both years were obtained in the Nagyeged terroir samples. The berry skin and seed astringency decreased significantly during ripening both years, and there were significant differences in this respect between regions as well. The vegetal character of the berry skin and pulp were equally decreased during ripening in both years, but in 2011 major differences between regions were found. In the evolution of pulp and mostly the berry skin fruity and spicy character the ripening processes and in particular the terroir effects proved to be dominant. Concerning the presence of the primary aroma compounds, the Nagyeged parcel's results were emerged. In all parcels and both years, significant increase in berry sugar intensity was found. In 2011, the acidity shown to decrease during maturation, while the acid quality (composition) in both years significantly improved by postponing the harvest date. In 2011, however, due to the extremely dry vintage several physical and quality parameters (berry skin separability, juiciness, vegetal flavour, drying taste of the phenolic compounds, quality of the acids etc.) the strong overriping caused adverse effects, which justify an earlier implementation of the harvest, especially in the unfavourable water supply areas (Nagyeged).

The berry sensorial analyses can effectively used in the ripening process monitoring. In the extremely cool and humid year of 2010, the differences between regions were clearly showed, the greatest potential in terms of quality red wine production was shown by the Nagyeged hill (top and low) parcels, while in 2011 all plots were suitable for the high quality wine production

Because of the extreme vintage effect due to our continental climate, the right timing of the harvest in a given parcel, can be established only by the use of the result of long standing term experiments. A database from the grape sensory test results complemented by the results of the classical chemical analyses, can be effectively applied in the practice for the individual grapevine parcels.

\section{Acknowledgement}

The project was partly supported by „az Emberi Erőforrások Minisztériuma által biztosított Kutató Kari Kiválósági Támogatás - Research Centre of Excellence 8526-5/2014/TUDPOL".

\section{References}

Deloire, A. (2013): Wine aroma and grapevine berry ripening: How to capture the complexity. Wine \& Viticulture Journal, 5: 65-68.

Le Moigne, M. - Maury, C. - Bertrand, D. - Jourjon, F. (2008): Sensory and instrumental characterisation of Cabernet Franc grapes according to ripening stages and growing location. Food and quality preference, 19: 220-231

Martinez, L. (2002): La dégustation des baies de raisin. Revue des Oenologues, 105: 19-21.

Morrison, J.C, Noble, A. C. (1990): The effects of leaf and cluster shading on the composition of cabernet sauvignon grapes and on fruit and wine sensory properties. Am. J. Enol. Vitic 3: 193-200.p.

Rousseau J. (2001): «Suivi de la maturité des raisins par analyse sensorielle descriptive quantifiée des baies. Relation avec les profils sensoriels des vins et les attentes des consommateurs», 849-850: 719-728.

Rousseau J., Delteil, D. (2000/a): Présentation d'une méthode d'analyse sensorielle des raisins. Principe, méthode et grille d'interprétation, Revue Française d'Enologie; 183: 10-13.

Rousseau J., Delteil, D. (2000/b): «Evaluer la maturité en dégustant le raisin», Guide de la vinification rhodanienne (julio); 4: 23-24. 